\title{
La recepción de la imagen. Una reflexión antropológica sobre la representación del indio en México
}

\author{
Image Reception. An Anthropological Reflection on \\ the Native Representations in Mexico.
}

\author{
Mariana Petroni \\ Centro de Investigaciones y Estudios Superiores en Antropología Social. DF. \\ México. \\ marianapetroni@hotmail.com
}

Resumen • Este artículo busca desarrollar una reflexión sobre el uso de la fotografía en el trabajo antropológico, tanto pensando la imagen como un instrumento para la realización del trabajo etnográfico, como para buscar comprender el papel de la fotografía, en su rol de formadora de representaciones sociales y su repercusión entre los que la reciben. Para ello será analizada la recepción de las fotografías del antropólogo e indigenista mexicano Julio de la Fuente entre los indígenas zapotecos del estado de Oaxaca, al sur de este país.

Palabras clave: fotografía, representación social, México, indígenas, recepción.

Abstract - The following paper presents a reflection on the use of photography in Anthropology, so as to consider the image as an instrument of ethnographic work as well as to comprehend the role of photography in the formation process of social representations and their repercussions among those who receive it. For this, the paper will analyze the reception of the photographs by Mexican Anthropologist and Indigenist Julio de la Fuente among the Zapoteco natives in the Oaxaca state at the South of Mexico.

Keywords: photography, social representation, Mexico, natives, reception.

\section{INTRODUCCIÓN}

Este artículo es parte de una investigación (Petroni, 2008a; 2008b) en la que buscó comprender la representación del indio en la antropología y en el indigenismo mexicano a partir de una propuesta que entiende la fotografía como una práctica cultural semióticodiscursiva, es decir, como una práctica que se establece y soluciona su funcionamiento 
no sólo en la dimensión simbólica, ya que ésta se encuentra condicionada por la praxis socio-cultural de los hombres que a través de ellas se apropian del mundo natural, social e imaginario en que viven.

A partir de la premisa anterior indagué sobre la representación del indio en las fotografías del antropólogo e indigenista mexicano Julio de la Fuente, quien, entre los años 1938 y 1941, realizó una investigación antropológica entre los zapotecos de Yalálag (De la Fuente, 1949) — comunidad ubicada en la Sierra Norte del estado de Oaxaca-, que tuvo como objetivo determinar las características culturales de indios y mestizos, así como los factores causales del cambio cultural entre ambos grupos.

Durante su investigación Julio de la Fuente tomó 211 fotografías de la región, que fueron analizadas tanto a partir del proceso de constitución de sentido de las imágenes como los que contextualizaron su producción, concluyendo en su consumo o recepción. A partir de las reflexiones iniciales sobre la recepción de imágenes realizadas anteriormente, presento este artículo que busca conocer cómo los habitantes de la Sierra Norte zapoteca reciben hoy día las fotografías tomadas por Julio de la Fuente, que indaga en la identificación con ellas, y que establece los cambios y continuidades percibidas en su realidad, a partir de lo que pueden observar en éstas. Así también, dar cuenta de una reflexión sobre el uso de la fotografía en el trabajo etnográfico, sus posibilidades y límites.

\section{LA FOTOGRAFÍA COMO FRAGMENTO}

Partiré, entonces, de la premisa que considera que una de las características centrales de la fotografía, según Susan Sontag, es el proceso mediante el cual sus usos originales se modifican y son suplantados por otros, dado que la fotografía es un mero fragmento, y su peso moral y emocional depende del lugar dónde se inserta (2006). A partir de ello puedo afirmar que una fotografía cambia según el contexto desde dónde se observa, de tal manera que la recepción de las imágenes tomadas por Julio de la Fuente debe ser comprendida a partir de las circunstancias en las cuales son vistas ${ }^{1}$.

Son las diferencias culturales, percibidas a través de un contexto específico, las que marcan las formas de apropiación de estas imágenes, ya que dichas diferencias son las que particularizan el lugar desde el cual el espectador parte para significar lo que está plasmado en la fotografía, y son estas particularidades las que deben ser aprehendidas cuando buscamos comprender la recepción de las fotografías. Esta percepción de la fotografía se sitúa sobre la diferenciación entre lo que se puede llamar «foto del fotógrafo» que implica una escenificación significativa, y, la «foto del espectador», que añade una relación subjetiva, a partir de la cual cada espectador se recluirá, apropiándose de determinados elementos de la foto, que serán para él como pequeños fragmentos sueltos de lo real (Rodríguez Gutiérrez, 1995: 242).

Para comprender la «foto del espectador» observada por los habitantes de Yalálag, buscamos comprender cómo determinados sectores de esta comunidad perciben las fotografías de Julio de la Fuente. La comprensión de la recepción de las fotografías es un

1 La observación de la recepción de las fotografías se dio fuera del ámbito de los museos, y se situó junto a los habitantes de la comunidad de Yalálag, en donde Julio de la Fuente realizó largos períodos de trabajo de campo, y en donde muchos de sus habitantes aún lo reconocen y lo estiman. 
intento por entender la mirada con que los yalaltecas se observan a sí mismos y a su historia.

Para comprender la recepción indígena de las fotografías de Julio de la Fuente fueron realizadas entrevistas informales y a profundidad a partir de un álbum compuesto por 95 fotografías. Las imágenes que compusieron el álbum fueron elegidas a partir de dos características: 1) calidad de la imagen y que permitieran su observación; 2) los temas más característicos en la obra de Julio de la Fuente y por lo menos la existencia de una foto por tema. En consecuencia, el álbum cubrió las principales temáticas abordadas por Julio de la Fuente en sus imágenes, así como también otras consideradas menos relevantes por la poca cantidad de fotografías.

Las 19 entrevistas dirigidas fueron llevadas a cabo con distintas personas del pueblo, tanto con habitantes «comunes» que me ofrecieron una mirada general sobre las fotografías, así como con otros que tuvieran un conocimiento particular sobre determinada actividad y pudieran ofrecer una visión más profunda sobre temáticas específicas. Además de las entrevistas dirigidas busqué complementar, a partir de la observación participante y de entrevistas abiertas, la información recolectada en las que intenté percibir, más allá de los datos duros, la parte subjetiva que involucra la recepción de las fotografías, tales como sus emociones, sus interpretaciones del pasado, etc., así como de acceder a la vida diaria de la comunidad.

Las entrevistas realizadas se centraron, principalmente, en cinco aspectos: 1) si la persona que observa la fotografía se identificaba con ella; 2) si percibía cambios en su realidad a partir de lo que retrata la imagen; 3) qué le llamaba más su atención; 4) la libre asociación y; 5) qué haría con las fotografías.

Estas preguntas se basan en ciertas aportaciones teóricas de algunos autores que han reflexionado sobre la recepción, sin embargo, como éste ha sido un tema aún poco explorado, este intento de análisis se desarrolló a partir de valoraciones personales de cómo se fue desenvolviendo el proceso de percepción de las imágenes por los sujetos entrevistados.

Es importante señalar aquí la importancia de la existencia de un álbum de fotografía en mis manos como medio facilitador al acceso a la comunidad, así como la entrada a espacios que sin la fotografía no me hubieran permitido con tanta facilidad.

México es un país conocido por su diversidad cultural, por la existencia de diversas comunidades indígenas y por la extensa investigación que se ha logrado sobre estos grupos, sin embargo la relación antropólogo-sujeto se ha ido desgastando a partir de la no existencia de la reciprocidad en el trabajo antropológico de muchos investigadores. No obstante, debo reconocer que la comunidad yalalteca, que ya ha recibido la visita de varios investigadores, me recibió de manera abierta a la realización de la investigación. Entretanto, las fotografías que Julio de la Fuente había tomado de la comunidad abrieron las puertas de manera más rápida, permitiéndome abordar temas e historias personales con mayor facilidad, ya que muchos entrevistados se sintieron cómodos al hablar sobre sí mismos a través de las fotografías, permitiendo con ello que yo en pocas horas conociera sus historias de vida y sus realidades de una manera más profunda y cercana. Esta vertiente poco explorada de las fotografías podría, tal vez, ser una de las aportaciones de la antropología visual al trabajo de campo, ya no como congeladora de un tiempo específico sino como una puerta hacia el entrevistado y su realidad. 
Desde mi experiencia particular como mujer extranjera en un lugar desconocido, en donde la población se comunica gran parte del tiempo en zapoteco, el álbum de fotografía que cargaba me permitió, muchas veces, acercarme a las personas sin ningún motivo aparente. Las fotografías antiguas de Julio de la Fuente abrieron puertas, iniciaron pláticas, como también me permitieron ingresar en interminables diálogos en zapoteco, en los cuales yo no hacía parte. Por ello puedo afirmar que la lengua fue uno de los principales obstáculos para la comprensión de la recepción de la fotografías, como también para la observación participante, sin embargo logré reunir suficiente información para el desarrollo de mi análisis.

La primera pregunta de la entrevista — si la persona que observa la fotografía se identifica con ella-buscó conocer si las características definitorias de los yalaltecas presentadas por De la Fuente correspondían o no a la forma cómo estos habitantes se perciben a sí mismos, haciendo con ello un juego entre la perspectiva indigenista de lo indio plasmada en su obra y la autopercepción.

La obra de Julio de la Fuente y sus imágenes se basan, inicialmente, en una relación ilustrativa, de testimonio de una realidad que el texto etnográfico busca, para finalmente, y a partir de conceptos teóricos, precisar y comprender.

El estilo documental de las imágenes del fotógrafo abarca desde la fotografía taxonómica, que retoma de cierta manera el modelo de registro de los grupos indígenas utilizada por diversos fotógrafos y científicos en el período inmediatamente anterior, la fotografía de ruinas arqueológicas y objetos prehispánicos, en un estilo "catálogo de museo» y la fotografía "costumbrista» de tipos populares tan marcada en los modelos fotográficos del siglo XIX; sin embargo resalta una óptica modernista de mayor movimiento de las imágenes, como también la inclusión de temáticas sociales como la pobreza y el alcoholismo.

Desde su mirada De la Fuente participó de la construcción de la imagen de los indios como sujetos de la acción del Estado, en la cual la diferencia debería transformarse en igualdad. Debido a sus intentos de comprensión de su realidad surgen imágenes de «tipos» catalogados, creando un índice del cambio cultural - de vestimenta- entre los zapotecos de la Sierra Norte oaxaqueña. Son fotografías en las cuales aparecen, desde una toma frontal, la familia reunida, o sujetos aislados o en parejas, de frente y tres cuartos, mostrando la indumentaria típica del grupo o de la comunidad, o el cambio de esta indumentaria. Se muestra la vestimenta masculina y femenina, el fondo no es neutral sino que muchas veces incluye aspectos que caracterizan la vida en la región. Los fotografiados posan rígidamente, conscientes de estar frente a una cámara fotográfica; los rasgos físicos son aspectos secundarios, que demuestran una visión centrada más en la «cultura» que en la «raza», lo que denota la mayor influencia de la escuela antropológica culturalista en su percepción de la realidad, valorando la relatividad cultural de la diferencia.

El autor manifiesta a través de sus imágenes su concepción teórico-antropológica de lo indígena, principalmente las desarrolladas en sus primeros textos en los cuales define lo indio a través de características culturales como la vestimenta, la lengua, y las costumbres tradicionales. También por medio de sus imágenes, y de sus textos, resalta la importancia de las acciones indigenistas como formas de integración del indio a la sociedad nacional. No obstante, mediante sus imágenes el autor refleja los problemas de la nación, la miseria y marginación de los indígenas, así como la existencia de una diversidad contraria al ideal unificador. 
La segunda pregunta — si percibe cambios en su realidad a partir de lo que retrata la imagen- buscó explorar las señales de cambio cultural presentadas por Julio de la Fuente y la existencia de una apreciación o no al respecto por parte de los habitantes de Yalálag, así como su percepción en el presente.

La tercera pregunta partió de las aportaciones de Roland Barthes, quien busca comprender el interés particular por determinadas fotografías. A través de la definición de dos elementos, el studium, entendido como «la aplicación a una cosa, el gusto por alguien, una suerte de dedicación general, ciertamente afanosa, pero sin agudeza especial» (Barthes, 1997: 64), y el punctum, que, según el mismo autor, es un elemento que sale de la escena como una flecha y produce en el espectador puntadas, a partir de lo que busqué percibir cuáles detalles de las fotografías de Julio de la Fuente atraían la mirada de los habitantes de Yalálag. Es una manera de dar mayor énfasis a la mirada del Spectator o de aquellos que ven las imágenes fotográficas, en contraposición con la mirada del Operator, que en este caso específico sería Julio de la Fuente, el que operó la cámara.

La cuarta pregunta buscó entender las líneas de pensamiento desarrolladas a partir de las imágenes y, también la conexión entre las fotografías y la memoria social yalalteca. Se busca demostrar cuáles temas son más explotados a partir de la observación de las fotografías en un intento por comprender qué recuerdos surgen a partir de las imágenes tomadas por De la Fuente.

La última pregunta intentó comprender la importancia que se da a esta obra en la comunidad zapoteca y llama la atención hacia la necesidad de crear una mayor «atención cultural» para estas comunidades.

\section{YALÁLAG}

En la Sierra Norte del Estado de Oaxaca al sur de México (lámina 1), a 120 kms. de la ciudad de Oaxaca, se ubica la comunidad zapoteca de Villa Hidalgo Yalálag con una población de aproximadamente 2000 habitantes. Esta comunidad, la más importante del sector Cajonos, ubicado al noreste del Valle de Tlacolula, se destaca por su antigua importancia económica en la región y por ser la población zapoteca más cercana a los pueblos mixes.

Algunos de sus habitantes se dedican a la agricultura y producen principalmente maíz y caña de azúcar para el autoconsumo, sin embargo prevalecen las actividades comerciales y la producción de huaraches, que son comercializados en las ciudades cercanas de Villa Alta y Zoogocho, donde se realizan los mercados más importantes de la región.

Conectada con otros pueblos de la región y con la capital del estado por una carretera transitada diariamente por la compañía de autobuses La Flecha del Zempoálteptl, Yalálag se caracteriza, como muchos pueblos de la sierra, por su alto índice migratorio. La mayoría de sus habitantes, principalmente los jóvenes, se va a la ciudad de Oaxaca, al Distrito Federal o a Los Ángeles en los Estados Unidos a buscar otras maneras de sobrevivir.

Su gobierno, basado en las costumbres locales, es electo una vez al año por la Asamblea Comunitaria que se reúne para escoger a todos los miembros del ayuntamiento, que 
como ciudadanos deben cumplir su cargo durante un año sin recibir sueldos o ayuda monetaria de la comunidad.

La vestimenta tradicional ya no es utilizada por las yalaltecas, el huipil blanco bordado con flores que las diferencian de las demás habitantes de la sierra. Solamente algunas mujeres mayores aún preservan esta vestimenta. No obstante, y como afirman los mismos habitantes, la lengua zapoteca hablada en Yalálag es de las únicas que aún se preserva sin mucha influencia del español, pero muchos yalaltecas cuentan que los niños ya no hablan el zapoteco y por ello la lengua puede desaparecer.

Yalálag también es reconocida por sus conflictos internos de disputa por el poder del ayuntamiento. Miembros del Partido Revolucionario Institucional (PRI) y el grupo comunitario que se reúne a través del Centro Cultural Uken Ke Uken A. C. pelean por la inclusión o no de las tradiciones y costumbres en la administración del pueblo. Este pleito caracteriza el contexto social de Yalálag, que se divide entre los defensores de la «modernidad» por un lado y de la «tradición» por otro, como dos vertientes antagónicas que pueden "desarrollar» o "desaparecer» al pueblo según cada punto de vista.

Estas características generales me permiten presentar un breve panorama de la realidad que encontré en Yalálag, el cual será complementado a partir del análisis de la percepción de las fotografías.

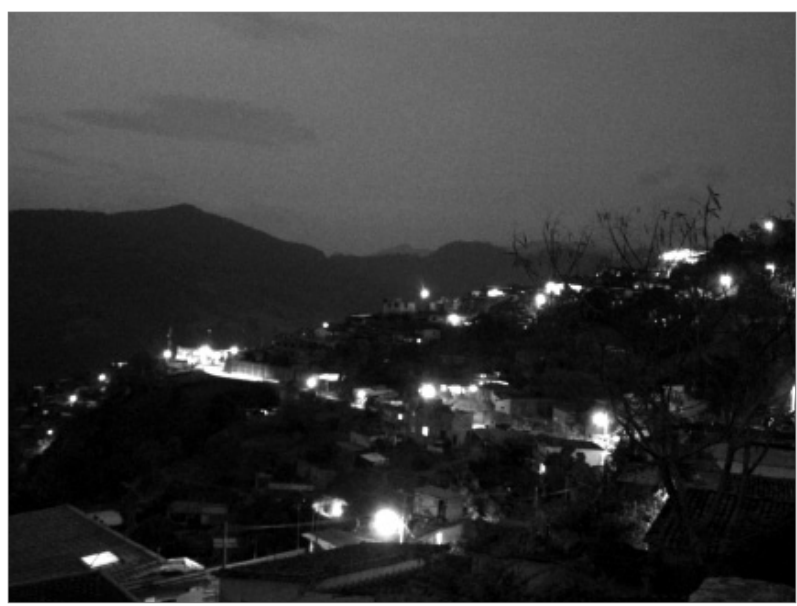

1. «Yalálag». Ernenek Mejía. Yalálag, 2007. 


\title{
VER LAS FOTOGRAFÍAS ME IDENTIFICO O NO CON LAS IMÁGENES DE JULIO DE LA FUENTE
}

\begin{abstract}
Comprender adecuadamente una fotografía [...] no es solamente recuperar las significaciones que proclama (es decir, en cierta medida, las intenciones explícitas de su autor), es también, descifrar el excedente de significación que revela, en la medida que participa de la simbólica de una época, de una clase o de un grupo artístico.
\end{abstract}

Pierre Bourdieu

La permanente tensión entre el proceso de creación e interpretación de la imagen adquiere nuevos matices en el análisis de su recepción. A través de la relación entre la mirada del fotógrafo y la del espectador la interpretación de la recepción busca comprender los mecanismos sociales que deconstruyen y reconstruyen la información transmitida por distintas miradas.

Utilizando la fotografía como espejo de lo real, la mirada yalalteca contemporánea buscó entre las fotografías de Julio de la Fuente la memoria, los recuerdos, las señales de un pasado existente. Es por medio de la asociación de la imagen con la memoria social, que percibimos la existencia de una identificación de los espectadores con las fotografías. A través de la búsqueda de parientes, conocidos, lugares y de la percepción de los cambios, los entrevistados reconocieron las fotografías como imágenes del pasado de su comunidad, de su historia.

Cuando les enseñaba el álbum con las fotografías de Julio de la Fuente a los espectadores (lámina 2), la primera reacción era la búsqueda de conocidos o parientes entre los fotografiados. La gran mayoría no reconoció a nadie, dejando siempre una expresión de decepción tanto consigo mismo como con la investigadora, ya que muchos entrevistados, principalmente los señores y señoras mayores creían que al no reconocer a nadie no podían colaborar con el estudio.

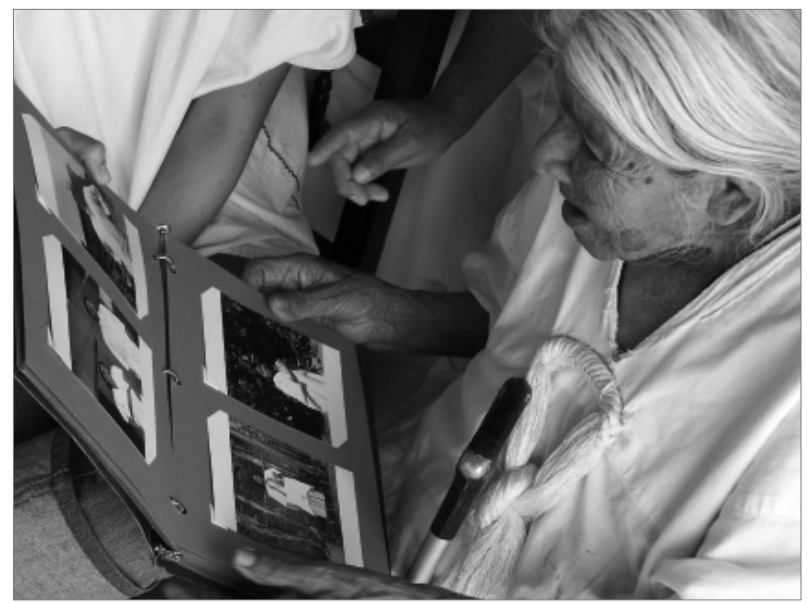

2. «La recepción». Ernenek Mejía. Yalálag, 2007. 
Entre los personajes que aparecen en las fotografías fueron reconocidos tres hombres, el primero don Samuel Vargas y su familia, quien fue el principal informante de Julio de la Fuente durante sus estancias en Yalálag. Samuel Vargas Hernández era productor de los sombreros de lana típicos de Yalálag y se dedicaba a comercializarlos en toda la región de la sierra y en la ciudad de Oaxaca. Algunos entrevistados afirmaron que «estaba más preparado» y por eso era el informante de don Julio. Según uno de los entrevistados Samuel Vargas "quería que la gente se educara, que no comiera en el suelo».

Samuel Vargas fue muerto en 1945, en una emboscada en el camino a Oaxaca por enemigos políticos, lo que llevó, según algunos entrevistados, a que De la Fuente abandonara su trabajo en Yalálag, por considerar a los yalaltecas «unos salvajes».

Otro personaje reconocido por algunos habitantes fue don Prisciliano Diego (lámina 3), quien aparece en las fotografías vendiendo huaraches y pieles curtidas en una de las galeras del mercado de Yalálag, que aún se realiza los martes por la mañana en el centro del pueblo. Este señor, que aún vive, fue reconocido por parientes y por sus hijos que también identificaron a su abuelo don Juan Diego, quien es nombrado en el libro de Julio de la Fuente como «el Principal», y es el único habitante de Yalálag que aparece con el fotógrafo en una imagen. Don Prisciliano Diego no habla español, por ello supe por su yerno que sí se reconoció en las fotografías.

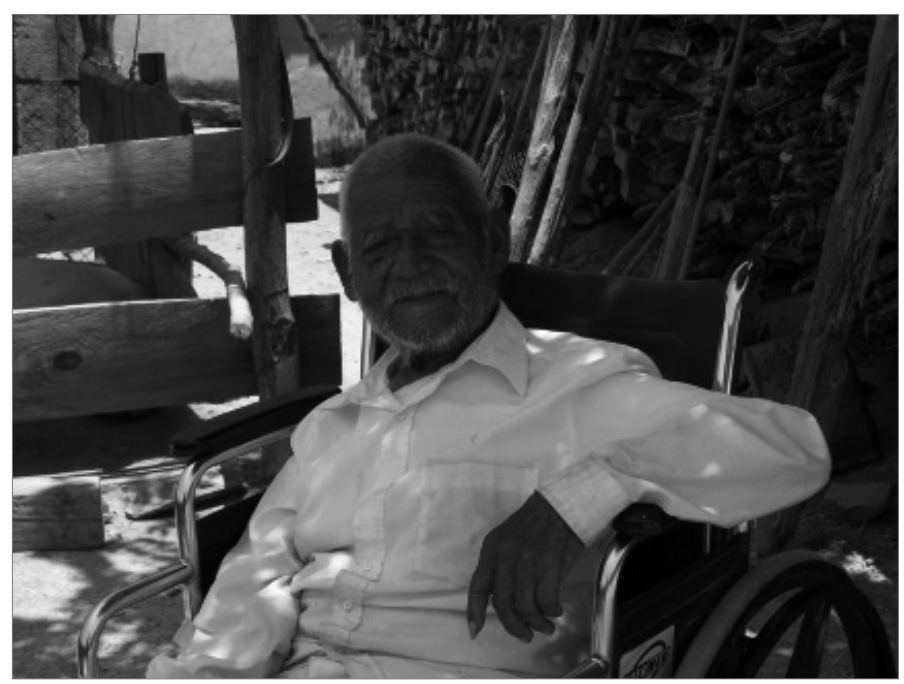

3. «Don Prisciliano Diego». Mariana da Costa A. Petroni. Yalálag, 2007.

Reconocer en la fotografía el retrato de un pariente significó para muchos entrevistados un acercamiento mayor con el álbum y con su propia memoria, pero no fueron estas imágenes, especialmente, las que activaron la memoria de los espectadores, sino todas aquellas en las que reconocían algún lugar, evento o característica típica del pueblo y que los llevaron a contar sobre su pasado o el de la comunidad, principalmente, sobre lo que se acostumbraba antes. Entre estas costumbres se destacó el uso del huipil yalalteca (lámina 4), compuesto por una pieza de manta blanca con flores o no una falda debajo y el rodete de lana de borrego en la cabeza. 


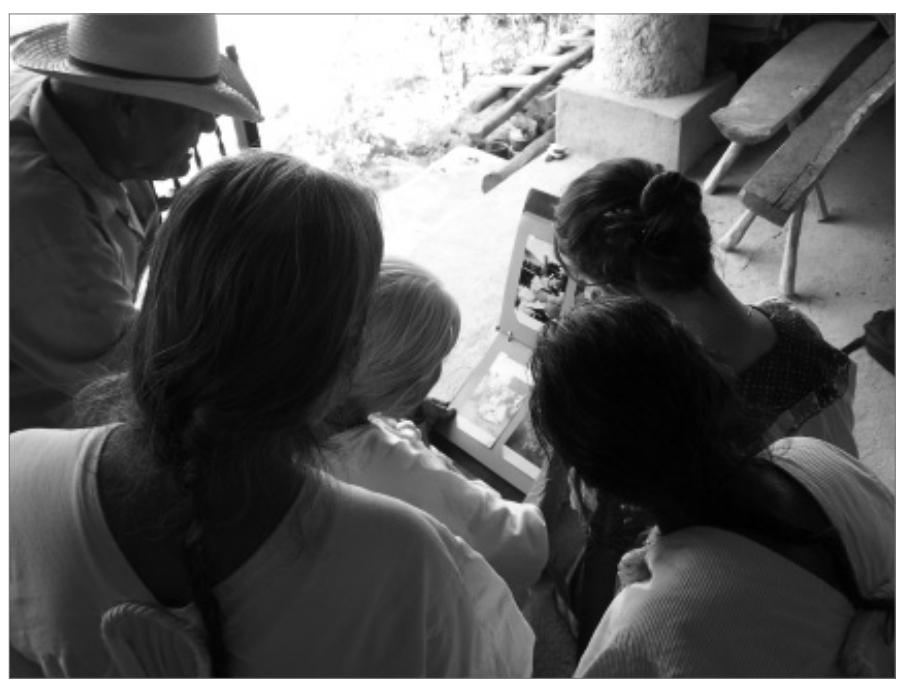

4. «Las fotografías de Don Julio». Ernenek Mejía. Yalálag, 2007.

Para comprender la percepción del huipil debemos antes recordar la situación política actual de Yalálag, dividida entre dos grupos locales que se disputan el poder del ayuntamiento. De un lado se encuentran aquellos habitantes vinculados al PRI y a los caciques de la región, que desde el período posrevolucionario son los encargados «de llevar el 〈progreso', la «modernidad y la ideología del Estado a las regiones más aisladas del país» (Aquino 2002: 37). La tarea de fomentar el "progreso" comunitario muchas veces significó dejar atrás sus costumbres, sus creencias y su lengua zapoteca. La relación de los habitantes de la comunidad con este partido ha garantizado el apoyo local a los candidatos oficiales, así como ha asegurado la participación electoral de los yalaltecas a favor del PRI.

Del otro lado se encuentra el Grupo Comunitario que desde la década de los sesenta lidera un movimiento en contra del cacicazgo local, basado en la idea de democratización del municipio a través:

de una elección pública en la que participan todos los ciudadanos del pueblo, además consideran que toda autoridad que se pretenda democrática debe: trabajar sin cobrar salario, consultar a la comunidad en todos los asuntos importantes, rendir cuentas, contar con un programa de trabajo aprobado por el pueblo, etc. (Aquino 2002: 40).

Sin embargo, este movimiento no se limitó a luchar en contra del cacicazgo local, sino que se enfocó también en la construcción de un modelo de gobierno y de sociedad alternativo basado en la idea de valoración de su identidad local y de transformación y revitalización de las, hasta ahora, representaciones negativas asociadas con su identidad.

La acción colectiva del Grupo Comunitario surgió a partir de la convicción de que sólo a través de la revaloración de su cultura podrían mejorar sus condiciones de vida y redefinir positivamente sus relaciones con el resto de la sociedad. Para la socióloga Alejandra Aquino, quien realizó una interesante investigación en esta comunidad:

la afirmación positiva de la identidad étnica entre los yalaltecas puede ser explicada, en primer término, por el nacimiento de un movimiento comunitario a nivel local y regional 
que refuerza los lazos de solidaridad y provoca las primeras reflexiones en torno a la cultura propia. Todo esto se desarrolló en un contexto nacional e internacional en el que se estaban redefiniendo las representaciones colectivas en torno a lo indio, lo que permitió que los yalaltecas encontraran en la mirada del «otro», [...] una imagen positiva de si mismos a partir de la cual pudieron comenzar a reconocerse y recrear en otros términos su propia identidad (2002: 89).

Este movimiento resultó, posteriormente, en la promoción de iniciativas centradas directamente en el rescate de las tradiciones consideradas por los mismos participantes como definitorias de su identidad, a partir de lo cual surge el Taller de Investigación y Difusión Zapoteca Uken Ke Uken A. C., como una instancia donde los yalaltecas, particularmente las elites, han definido la lengua, la agricultura tradicional, las expresiones artísticas y las formas de organización comunitaria, como los elementos constitutivos de su identidad.

Es a partir de estas premisas que este grupo percibió las fotografías de los huipiles yalaltecas que les mostré, como la reafirmación de la tradición local y la valoración positiva de su carácter indígena. Su mirada, dirigida hacia la necesidad de revaloración de la identidad y la cultura yalalteca, percibió las fotografías que retratan la vestimenta como la afirmación de que en el pasado se encuentran los valores importantes de la comunidad.

Los entrevistados relacionados directamente con la organización del movimiento del Grupo Comunitario y de las actividades llevadas a cabo en su taller de investigación ${ }^{2}$ valoraron el pasado con relación al presente calificando la realidad percibida en las imágenes como más bella, más limpia, cuando las mujeres vestían «el verdadero traje de la mujer yalalteca», y "cuando era predominante el trabajo».

Esta valoración del pasado y de la tradición a través de la exaltación del uso del huipil venía, en las entrevistas, siempre acompañada de afirmaciones sobre la importancia y el valor de la lengua zapoteca para la comunidad y las consecuencias de su creciente mezcla con el español. Entre los yalaltecas, uno de los referentes principales de adscripción identitaria es la lengua. En la actualidad, casi el total de la población residente en la comunidad tiene como lengua materna el zapoteco y lo utiliza en distintos espacios de la vida cotidiana. Pero, como pude observar, entre los jóvenes y los niños este idioma ya se está perdiendo, pues si bien muchos de ellos comprenden la lengua, ya no la hablan, y algunos no se interesan en aprenderla; afirman que es más importante aprender el inglés, ya que «es la lengua que se habla en el norte», es decir en los Estados Unidos, para donde quieren ir al terminar la secundaria.

Frente a esta perspectiva el Grupo Comunitario ha demostrado un especial interés por reivindicar la lengua zapoteca como un elemento identitario importante para la comunidad $^{3}$. La afirmación positiva de su lengua, a través de las actividades de este centro cultural, ha llevado a la población de la comunidad a comprender que su lengua tiene el mismo valor que el español (Aquino, 2002).

2 El Taller de Investigación y Difusión Zapoteca Uken Ke Uken A. C. surge como una institución por medio de la cual el Grupo Comunitario busca fomentar la cultura zapoteca a través de la realización de actividades culturales dirigidas, especialmente, a los niños. En su sede son realizados talleres de bailes tradicionales, se enseñan a los niños a escribir en zapoteco y es también donde la banda del taller, compuesta por niños, ensaya.

3 La primera iniciativa de rescate cultural promovida por el Grupo Comunitario fue la organización del Taller de Lecto-Escritura de la Lengua Zapoteca, que fue apoyado por un equipo de antropólogos del Instituto de Investigaciones Antropológicas de la Universidad Nacional Autónoma de México. 
La asociación entre tradición - huipil- y lengua vino algunas veces acompañada de otro elemento también reivindicado como uno de los componentes de la identidad yalalteca. La valoración de la agricultura tradicional, la importancia de ser campesinos "como requisito indispensable para ejercer su derecho a la libre determinación» (Aquino: 92), y el valor del maíz como un grano sagrado responsable de dar la vida. Por ello llamó la atención de algunos entrevistados la falta de fotografías sobre las actividades agrícolas, que anteriormente, en Yalálag además de corresponder a la producción de maíz, también se relacionaba con la cosecha de frijoles, chile de onza, caña de azúcar y calabaza.

Aunque el cultivo del maíz es reconocido por los habitantes de Yalálag como una actividad importante para la vida comunitaria, muchas familias han abandonado sus cultivos, en especial por el alto costo que implica su producción. El cultivo del maíz exige gran cantidad de mano de obra e implica una gran inversión de tiempo, por lo cual muchas familias de la Sierra Norte prefieren emigrar a los centros urbanos en el país o en el exterior, dedicarse a otras actividades económicas o comprar maíz de la Conasupo ${ }^{4}$.

Entre las fotografías de Julio de la Fuente tomadas durante sus estancias en Yalálag no hay ninguna que retrate el trabajo agrícola. El interés principal del autor por comprender el cambio cultural tal vez lo llevó a no considerar algunas actividades «tradicionales indígenas» que no se caracterizaban por su cambio sino por su permanencia, como la actividad agrícola. Por ello podemos tal vez justificar la falta de imágenes que las retraten. A lo anterior hay que sumar que la gran mayoría de sus fotografías fueron tomadas en el centro de la comunidad, es decir en la parte urbana del pueblo, por lo cual hay una predominancia de tomas de mujeres y niños, que a diferencia de los hombres que se dirigían al campo para cuidar de su cosecha, se quedaban en el pueblo para realizar las tareas domésticas (lámina 5).

\footnotetext{
La Conasupo (Compañía Nacional de Subsistencias Populares) llegó a la Sierra Norte en 1974 y desde entonces ha introducido un maíz muy barato y de mala calidad y, con la entrada del maíz de la Conasupo se han introducido nuevas plagas en la región que atacan al maíz almacenado por los yalaltecas, que tienen la practica de guardar el maíz durante varios años, para garantizar su alimentación en épocas de mala cosecha, como también atender a sus compromisos ciudadanos cuando dejan sus cosechas para dedicarse exclusivamente a la comunidad (Aquino, 2002).
} 


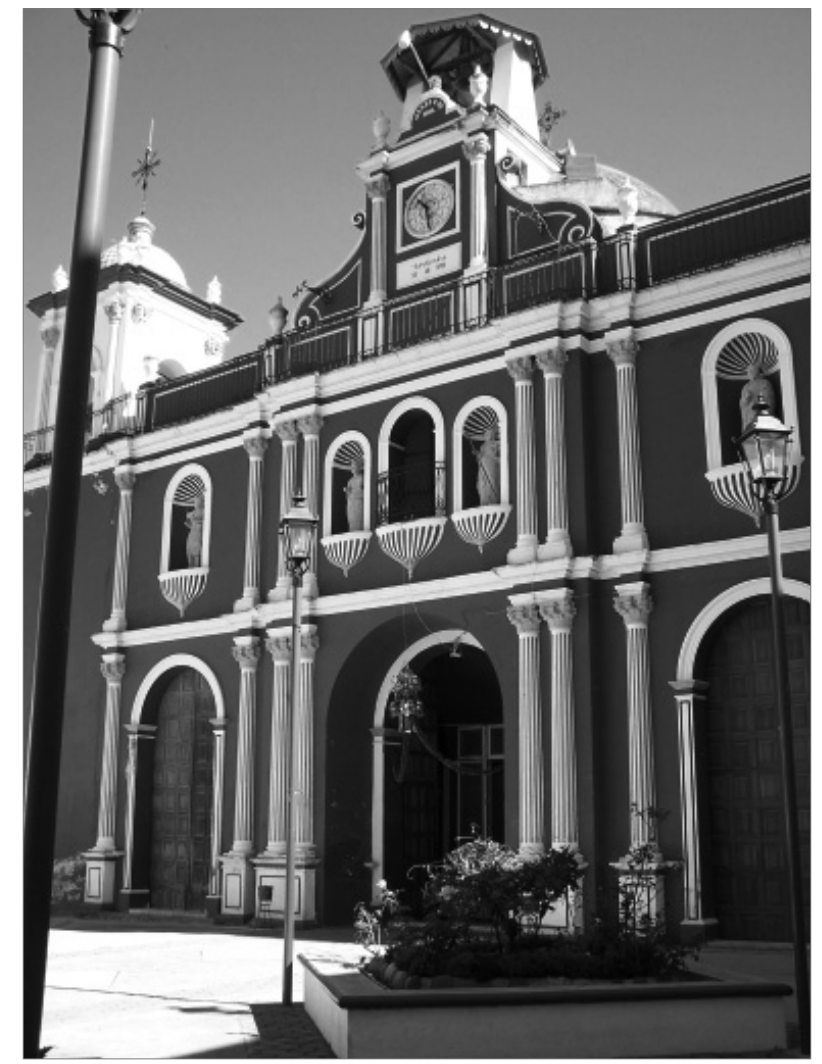

5. «lglesia de San Juan». Mariana da Costa A. Petroni. Yalálag, 2007.

Es importante mencionar que no sólo los organizadores y participantes del Grupo Comunitario percibieron la falta de fotografías de las actividades agrícolas de la comunidad, sino también otros que si bien no son parte directa de esta organización sí conocen las actividades del Taller de Investigación y preguntaron por las fotografías de la roza, de la milpa y la siembra. Estas personas, a diferencia de los participantes del movimiento contra el cacicazgo, no vieron al huipil como la afirmación de su tradición, sino más bien como otro elemento que se ha dejado de utilizar y se ha sustituido, según algunos a causa del precio de la manta; otros, principalmente las mujeres, por ser muy sucio y pesado para lavar. Las razones eran diversas, pero demostraban la diferencia en la percepción de la presencia o no del huipil en las imágenes. Este segundo grupo, conformado principalmente por yalaltecas que comercian productos de su huerto en el mercado de la comunidad los martes por la mañana, a diferencia del grupo anterior que había identificado a las mujeres vestidas con vestido "mestizo" como habitantes de otras comunidades, caracterizó las mismas como personas con dinero, que se dedicaban a actividades distintas a la agricultura y que como consecuencia tenían más contacto con la ciudad de Oaxaca (lámina 6). Muchos de los entrevistados que no usaron el traje tradicional durante su infancia o que su mamá no usaba el huipil, eran de familias que tenían como principal actividad económica la venta de café, el comercio de carne y la producción de huaraches. 


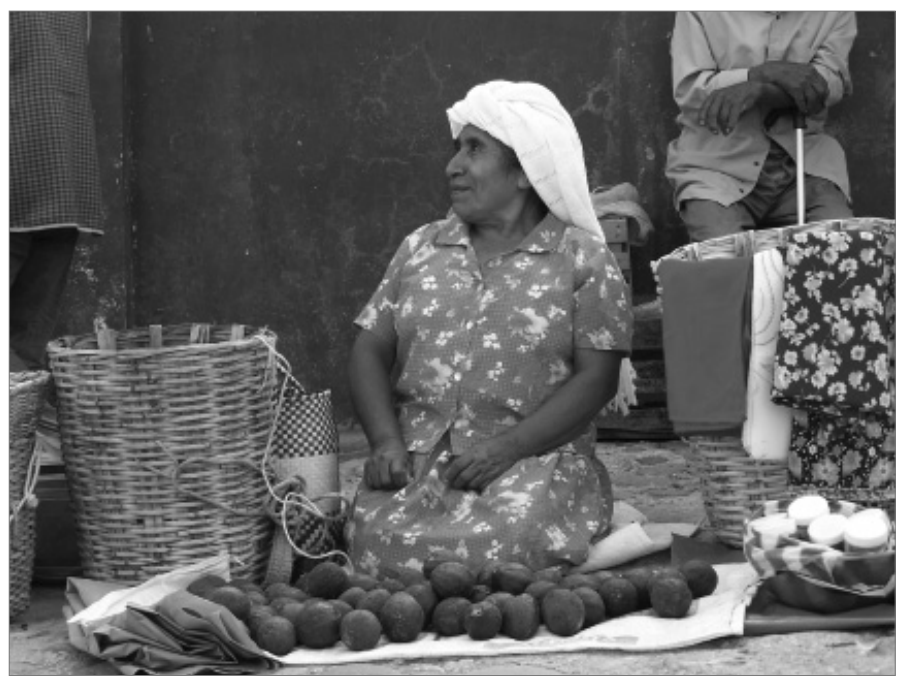

6. «Vendedora de aguacates». Mariana da Costa A. Petroni. Yalálag, 2007.

Esta primera incursión por la recepción de las fotografías de Julio de la Fuente me hace reflexionar, por un lado, sobre las diferencias de percepción de las imágenes entre grupos sociales, caracterizados en esta sociedad también por sus diferencias políticas; y; por otro, sobre la presencia de las características que definen al indígena según el indigenismo mexicano de la década de los cuarenta y cincuenta en México ${ }^{5}$, en el discurso yalalteca de reivindicación de su autodeterminación.

A partir de las observaciones anteriores podemos afirmar que los yalaltecas sí se identifican con las fotografías de Julio de la Fuente. Su mirada, a partir de sus características individuales, buscó en las fotografías elementos que desde su percepción personal caracterizaban el ser yalalteca. Puedo destacar la identificación de familiares y personas conocidas, así como lugares de la comunidad y el mercado por todos los entrevistados.

El huipil, retratado por De la Fuente como elemento de cambio cultural, fue el elemento mayormente percibido, aunque de diferentes maneras. La percepción estuvo marcada, principalmente, por las relaciones entre clases sociales. Así, desde las elites intelectuales de la comunidad las fotografías de la vestimenta tradicional yalalteca fueron vistas a partir de la afirmación del valor y de la belleza indígena, encontrando el antropólogo, en la mirada del «otro", la confirmación de la existencia de una imagen positiva de sí mismo.

Esta percepción marcada también por la pertenencia a un movimiento de reivindicación identitaria se funda sobre una serie de rasgos que retoman de cierta manera las características afirmadas desde el indigenismo de Estado como definitorias de lo indígena

\footnotetext{
En la década de los 40 y 50 en México fue el período en el cual se desarrollaron las principales instituciones indigenistas del país que basaban sus planteamientos y prácticas en la promoción del desarrollo de las comunidades indígenas a través del desenvolvimiento económico y de la educación, buscando de esta manera darles un carácter de igualdad frente a la comunidad mestiza que formaban la maza de la población mexicana. Estas acciones se traducían en una «aculturación planificada», entendida como la sustitución de valores y la transformación ideológica que correspondía a un estado cultural específico.
} 
en México. Más que un proceso de coincidencia o influencia del indigenismo sobre los movimientos indígenas, es interesante notar que estas particularidades son reclamadas por el movimiento yalalteca como parte de un movimiento de autodeterminación en el cual, paradójicamente, luchan tanto por la diferencia como por la igualdad, ya que al mismo tiempo buscan la obtención de derechos específicos, y demandan sus derechos ciudadanos que reiteran su intención de formar parte de la nación. La comprensión del proceso a partir del cual el movimiento del Grupo Comunitario retoma estas características impuestas por el indigenismo y las resignifica, queda como tema para ser estudiado en otra investigación.

Desde el otro punto de vista, las personas que no pertenecían al movimiento por la autodeterminación percibían al huipil como otro elemento de su realidad que se perdió frente a los cambios que llegaron con la carretera, el incremento de la migración, la disminución de la importancia del mercado, entre otras transformaciones que no significaron, esencialmente, la pérdida de su identidad indígena, sino más bien la transformación en su realidad.

\section{PERCEPCIÓN DEL CAMBIO}

Las investigaciones realizadas por Julio de la Fuente en la Sierra Zapoteca seguían las aportaciones del antropólogo Robert Redfield (1973) y buscaban localizar las características de las comunidades indígenas a lo largo de un continuum cuyos extremos son, por un lado, la sociedad urbana y, por el otro, la rural folk. Por lo anterior sus fotografías buscaron ilustrar los elementos característicos de estas transformaciones.

A partir de estos diagnósticos, afirmo que el objetivo central de Julio de la Fuente fue proponer acciones que permitieran la integración de las comunidades a la sociedad nacional a través de su evolución a un estado superior de desarrollo, que se daría a partir de la adopción, por parte de los indígenas, de elementos provenientes de «culturas más avanzadas» o de las sociedades urbanas. Creyendo en los beneficios de la «modernidad» como parte de la solución a la marginación de las comunidades indígenas, De la Fuente buscaba formular políticas de transformación de la realidad indígena, como la «castellanización» y el mejoramiento económico de estas comunidades.

Las imágenes que buscaron retratar el cambio de vestimenta son parte de esta preocupación, pues De la Fuente percibía el uso del huipil como parte de las transformaciones ocurridas en las sociedades indígenas a partir de su «contacto" con grupos mestizos de la población nacional, que llevarían a sus individuos a «dejar de ser indios» y con ello ser parte de la cultura nacional.

Entre los entrevistados solamente uno percibió en las imágenes de Julio de la Fuente el cambio cultural a través de la vestimenta, el entrevistado expresó: «Pues es impresionante [...] la señora ya viste a su niña en vestido y aquí trae el huipil [...]». También percibió que muchas mujeres en las imágenes ya traían el vestido y muchos niños zapatos, y afirmó:

[...] en el momento que llegan las modas acá en el pueblo la gente se transforma su conciencia, que es mejor lo que viene de afuera que lo nuestro, y ahorita pues ya son pocas las mujeres con huipil que quedan acá en el pueblo. 
Esta afirmación, que provino de un miembro del Grupo Comunitario, coincide de cierta manera con los objetivos de De la Fuente. Al considerar la pérdida de determinados elementos que conforman su cultura como la pérdida de su identidad, perciben la disminución del uso del huipil como uno de los síntomas de esta desaparición y por consecuencia del desgaste de la cultura local. Ésta fue la única asociación clara de percepción del cambio cultural con lo que estaba, de manera estricta, plasmado en la imagen; las demás apreciaciones del cambio surgieron a partir de la comparación entre lo que estaba retratado en las fotografías y el presente.

Entre los zapotecos de la sierra uno de los diferenciadores comunitarios es la vestimenta, a través de la cual, principalmente las mujeres son identificadas. Debido a ello, muchas veces, los entrevistados llamaban la atención sobre la pertenencia comunitaria de algunos fotografiados a partir de su traje y con ello identificar lugares y comunidades que estaban clasificados en el archivo El Mundo Indígena como Yalálag, pero que eran otras localidades de la Sierra. Desde el contexto local, el cambio de vestimenta puede ser entendido como la pérdida de una de sus características diferenciadores y de pertenencia comunitaria. A partir de esta perspectiva se puede pensar que el elemento utilizado por De la Fuente para caracterizar lo folk o indígena, tiene para los habitantes de esta región un significado de diferenciación regional, que marca las relaciones sociales en la Sierra Norte y por ello surgió como un elemento a partir del cual los yalaltecas se identificaban con las imágenes, como también un elemento a partir del cual muchos entrevistados percibieron, cada uno desde su punto de vista particular, los cambios en la comunidad. El cambio de vestimenta no significa sólo la pérdida de otro carácter cultural que los diferencia frente a la sociedad nacional, sino también uno de sus símbolos de pertenencia comunitaria.

Además de la pérdida de la vestimenta tradicional, la diferencia existente entre el mercado (lámina 7) retratado por Julio de la Fuente y el mercado que se realiza hoy en el centro de Yalálag fue también percibida. De la Fuente describe el mercado en su obra como el medio a través del cual «se compra y vende casi todo lo que producen la agricultura e industria comarcanas, al constituir el principal mecanismo para la distribución comercial y la adquisición de dinero» (129). Sus imágenes retratan la cantidad de personas que frecuentaban la plaza, los productos comercializados y los diversos orígenes de vendedores y compradores que acostumbraban acudir a la plaza en Yalálag.

La plaza de Yalálag, en la década del cuarenta, ocupaba el segundo lugar en importancia en la región, después del mercado de Zoogocho, «asignándosele este lugar por la apreciación general del número de pueblos dependientes, vendedores y compradores y por el volumen de ventas» (De la Fuente: 129). El mercado que se realizaba los días martes, como hasta hoy, se caracterizaba por ser un importante depósito de maíz al que concurrían zapotecos y mixes, y era también donde se concentraba el café producido en regiones cercanas y de allí llevado a Oaxaca. Muchas familias yalaltecas prosperaron, en esta época, a través de la comercialización del café de la Sierra en la capital del estado.

Hoy (lámina 8) la plaza concentra algunos vendedores de la comunidad que comercializan verduras y frutas, otros que traen productos de plástico de Oaxaca y habitantes de comunidades cercanas que venden artículos específicos de su pueblo, como el mamey que se da solamente en tierras frías. Los primeros compradores llegan a las siete de la mañana y a las diez los vendedores ya están levantando sus productos. 


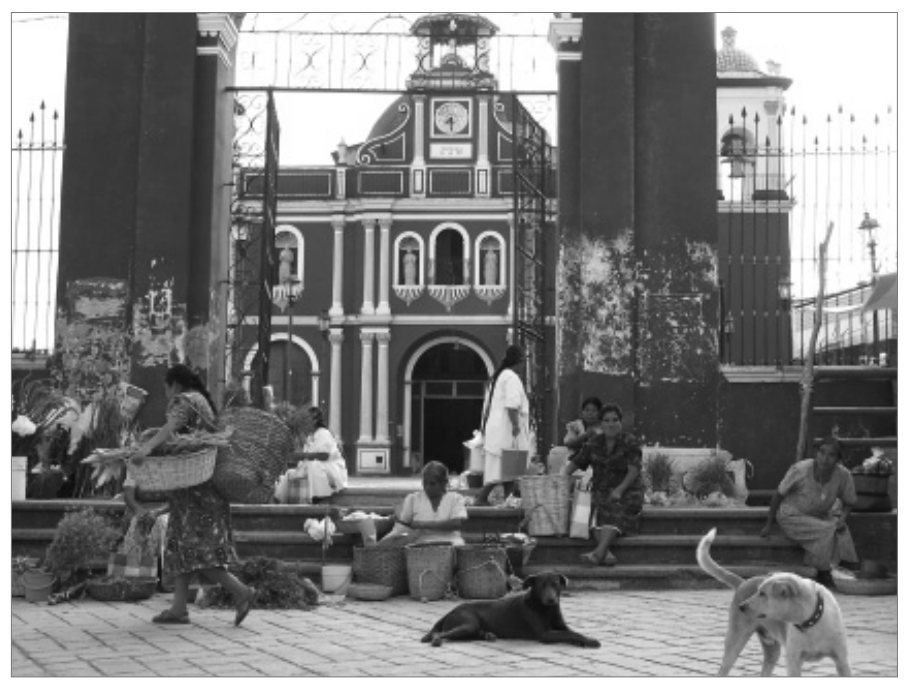

7. «El mercado». Mariana da Costa A. Petroni. Yalálag, 2007.

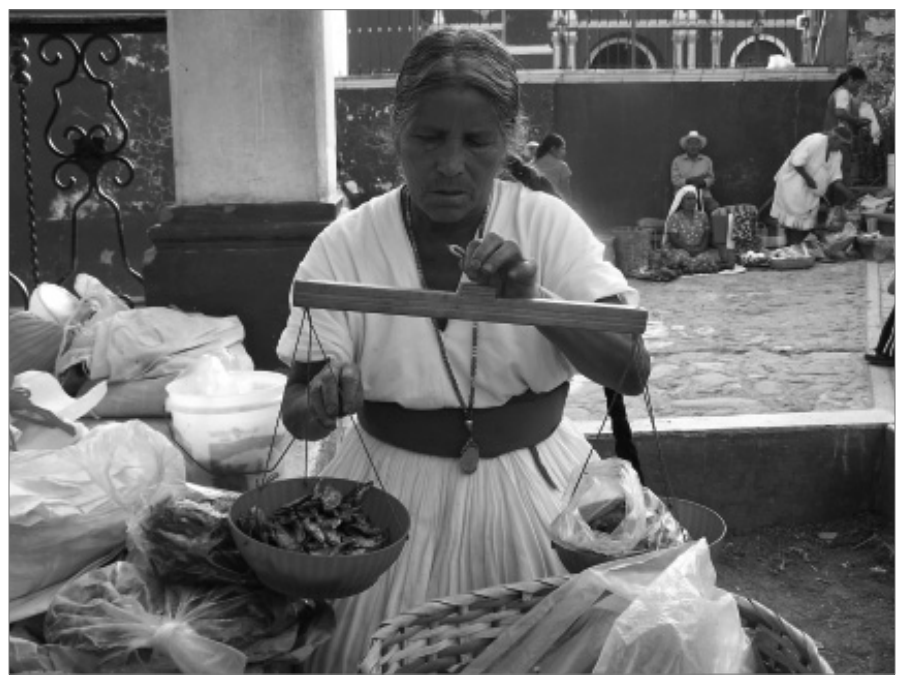

8. «Pescado seco». Ernenek Mejía. Yalálag, 2007.

Esta transformación no sólo llamó mi atención sino también de muchos que vieron las fotografías. Los jóvenes que no vivieron el auge del mercado del pueblo (lámina 9), conocían las historias de su importancia, sin embargo no habían visto imágenes de esta diversidad de productos y personas. No mostraron sorpresa, sino interés por conocer las diferencias de la plaza de antes y la plaza de hoy. Entre los mayores surgía un dejo de nostalgia, ya que el mercado representaba para muchos la imagen de la importancia y la prosperidad que caracterizó la comunidad. 


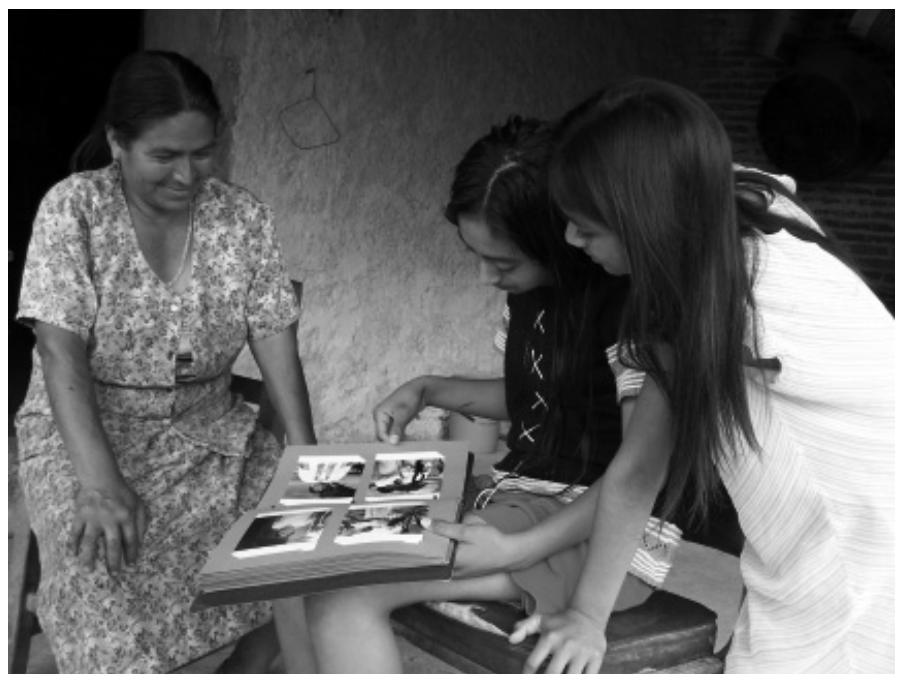

9. «La historia de Yalálag». Ernenek Mejía. Yalálag, 2007.

Hasta la década del sesenta, la carretera que venía de la capital del estado llegaba a la Sierra Norte hasta Yalálag, por lo cual todos los productos que salían o entraban a la sierra tenían que pasar obligatoriamente por Yalálag, lo que la convirtió en uno de los más importantes centros comerciales de la región, lo que ocasionó la prosperidad de muchos yalaltecas que se dedicaban a comprar o producir artículos típicos de la sierras y venderlos en la ciudad de Oaxaca. Con la ampliación de la carretera hacia en municipio de Villa Alta, que se ubica ya en la frontera del estado de Oaxaca con el estado de Veracruz, el pueblo perdió su importancia, lo que ocasionó el empobrecimiento de la población, la decadencia del mercado local y el aumento de la migración.

A través de las fotografías del mercado muchos entrevistados relataron las mudanzas ocurridas en la comunidad durantes estos años. Una de ellas fue la sustitución de los materiales producidos en la región como la cerámica, por productos y utensilios de plásticos, lo que significa para muchos, principalmente jóvenes, el aumento de la contaminación del ambiente. Estas imágenes «negativas» eran siempre asociadas con la decadencia del mercado yalalteca, así como con la pobreza de la comunidad y de la región.

Esta percepción del cambio y de las transformaciones que ocurrieron en la comunidad a partir de la llegada de la carretera, asociados al surgimiento de aspectos negativos, demuestran que desde la perspectiva de los indígenas de Yalálag los cambios defendidos por De la Fuente como necesarios para la integración de estas comunidades a la cultura nacional, no los llevaron a una real integración a la vida nacional, sino a la persistencia de la marginación en la cual ya vivían y a la pérdida paulatina de practicas tradicionales como el cultivo de la tierra. Puedo, así, afirmar que en Yalálag la dicotomía tradición y modernidad se caracteriza tanto entre jóvenes como entre adultos, como un conflicto ya que significa al mismo tiempo el acceso a determinadas tecnología y mejoras en la calidad de vida de la población, como también la pérdida de elementos culturales importantes y sus consecuencias sobre la vida económica del pueblo. Independiente de si son o no parte de la elite indígena local defensora de las tradiciones de la comunidad, los yalaltecas 
(lámina 10) entienden ambos procesos como contradictorios y separados que llevan, por un lado, a salir de su «atraso" aunque a cambio dejar sus costumbres, o por otro, "permanecer indígenas» pero aislados de la sociedad nacional y de las mejoras tecnológicas provenientes de ella.

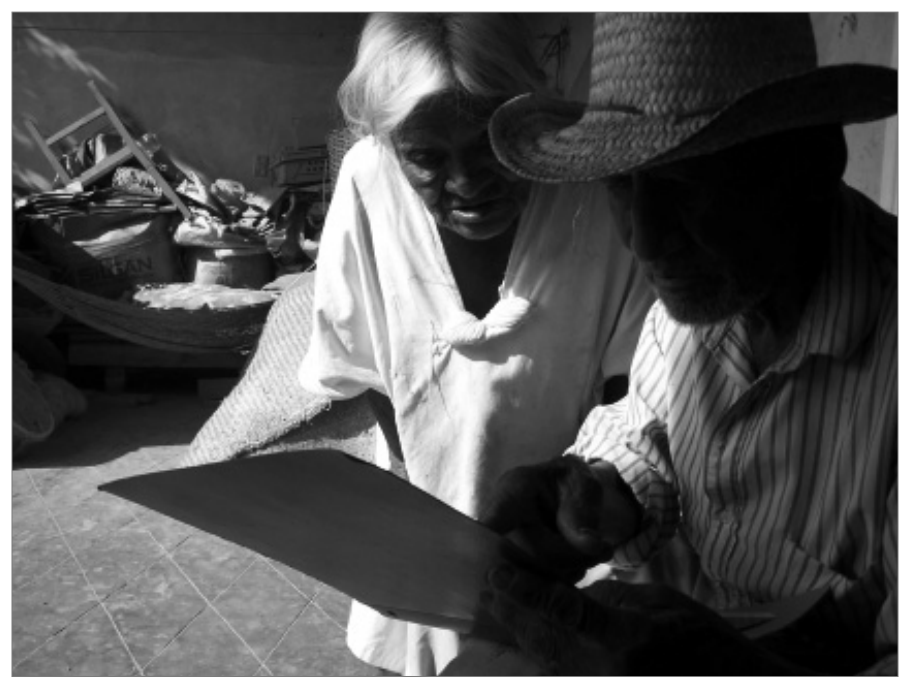

10. «Las fotografías de antes». Ernenek Mejía. Yalálag, 2007.

\section{EL PUNCTUM}

Roland Barthes (1997) define el punctum como un elemento que se destaca en la fotografía y produce en el observador puntadas. Al observador le llama la atención, entonces, una mirada, un rostro, un árbol, la vestimenta de alguien, y le causa algún tipo de sensación que le marca, le punza.

Desde la perspectiva del álbum que enseñé a los entrevistados en Yalálag percibir y registrar cada elemento en cada fotografía que les llamaba la atención era prácticamente imposible. Los elementos se perdían entre una fotografía y otra o ganaban distinta importancia entre tantas imágenes. Era, a diferencia de la propuesta de Barthes, el conjunto de las imágenes, es decir el álbum como un todo, lo que causaba algún tipo de sensación entre los entrevistados. Entre los adultos mayores la nostalgia marcaba cada imagen, los recuerdos de cómo era antes surgían durante las entrevistas, ya entre los más jóvenes las impresiones fueron más diversas iban desde el interés por conocer el pasado de su comunidad hasta el total desinterés. Por lo anterior elegí aquí destacar una única fotografía que entre la gran mayoría de los observadores llamó la atención por la presencia de un elemento: una olla de barro que era comercializada por los mixes, un grupo étnico subordinado económicamente a los zapotecos y que viven bastante cerca de Yalálag. 
Principalmente entre las mujeres (lámina 11) este objeto causó sorpresa, era señalado y venía acompañado de comentarios sobre su uso. Estas ollas comercializadas por lo mixes, eran utilizadas por los yalaltecas para el almacenamiento de agua y para la producción de bebidas y comidas tradicionales.

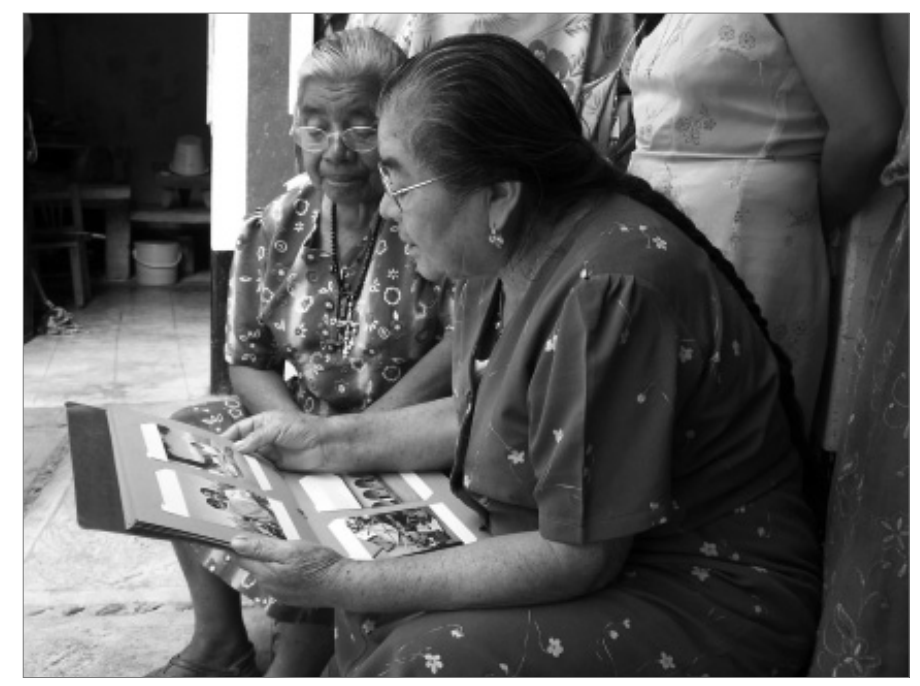

11. «Volver a ver». Ernenek Mejía. Yalálag, 2007.

Aún se ven en los patios de algunas casas de este pueblo estos cantaros llenos de agua que se utilizan para lavar los trastes o algún utensilio doméstico, no obstante en el mercado, como lo había mencionado anteriormente, no se comercializan artefactos de cerámica o barro. Hoy, con el agua entubada la necesidad de almacenarla casi ha desaparecido, la comida es preparada en ollas de metal y la bebida tradicionales ya no se prepara. Como un elemento poco frecuente en la vida diaria yalalteca, la olla mixe surgió entre las fotografías como un elemento de recuerdo no sólo del objeto en sí, sino también por las actividades que estaban relacionadas con él, desde el comercio mixe hasta la producción de la bebida.

A partir de la valoración de las imágenes en su conjunto, la perspectiva yalalteca demostró que un álbum fotográfico tiene un significado distinto y una importancia diferente frente a una imagen aislada. Más allá de percibir los elementos que significan cada una de las fotografías, se observó por medio de las imágenes cómo emergieron historias, recuerdos, opiniones que forman parte de la vida comunitaria yalalteca y conforman una perspectiva distinta sobre el papel de la fotografía en la investigación social.

\section{LA FOTOGRAFÍA Y MI PASADO}

Antes de seguir con la última pregunta aclaro aquí que la libre asociación fue utilizada durante toda la entrevista. Así, a partir de la libertad dada a los entrevistados sobre 
cada fotografía o cada conjunto de imágenes, los yalaltecas contaban algún episodio de su vida, explicaban cómo se producía determinado artículo como los huaraches, o contaban cómo sobrevivía entonces su familia. Y fue a través de la libre asociación que ellos buscaron fotografías inexistentes, y pude percibir que entre las imágenes tomadas por De la Fuente faltaron no sólo las fotografías de las actividades en el campo, como ya fue señalado, sino también de la producción de huaraches, que hasta hoy es visible por toda la comunidad, ya que entre las casas se ven las pieles colgadas secando al sol; o aun la producción de sombreros, actividad a la que se dedicaba don Samuel Vargas, el informante principal de Julio de la Fuente.

Fue también a través de la libre asociación que percibimos que Julio de la Fuente es reconocido en Yalálag especialmente por la elite intelectual comunitaria, la cual conoce su libro sobre Yalálag, o debido a que lo conocieron personalmente en la década del sesenta cuando volvió a la comunidad para la inauguración de la escuela secundaria. También es conocido entre los adultos mayores que tienen algún recuerdo de sus primeras estancias en Yalálag, muchos de los cuales no recordaban su cámara fotográfica, pero lo reconocían como "paisano" porque había estado mucho tiempo en la sierra y hasta había aprendido a hablar el zapoteco.

Las fotografías fueron percibidas entre los yalaltecas como «una prueba incontrovertible de que sucedió algo determinado» (Sontag, 2006: 19), y como parte de la existencia de este pasado fueron valoradas como documentos que cuentan la historia de su pasado. Para todos los que las vieron éstas deberían ser mostradas a toda la comunidad, sin embargo muchos señalaron la importancia de que los niños, principalmente, eran los que deberían tener acceso a estas imágenes para "valorar lo que nos dejaron», "para que los jóvenes reflexiones como era antes», "para que conozcan las diferencias».

Como la preservación de un pasado extinto, las fotografías de De la Fuente, en el contexto yalalteca actual, marcado por la dicotomía tradición vs. modernidad, surgieron como documentos históricos de valoración de la historia local. Como lo afirma Sontag (lámina 12), la fascinación ejercida por las fotografías es un recordatorio de lo que ya no existe, pero también es una invitación al sentimentalismo. "Las fotografías transforman el pasado en un objeto de tierna reminiscencia, embrollando las distinciones morales y desmantelando los juicios históricos mediante el patetismo generalizado de contemplar tiempos idos» (Sontag: 106). Por ello, más allá de la defensa o recuperación de las tradiciones locales, las fotografías de De la Fuente son percibidas como un fragmento de la historia yalalteca que deben ser recuperados y conocidos por todos. Más allá del discurso antropológico y de la ideología indigenista de Julio de la Fuente, a partir de la mirada contemporánea yalalteca quedan plasmados los recuerdos, la memoria local y la valoración de una historia única. 


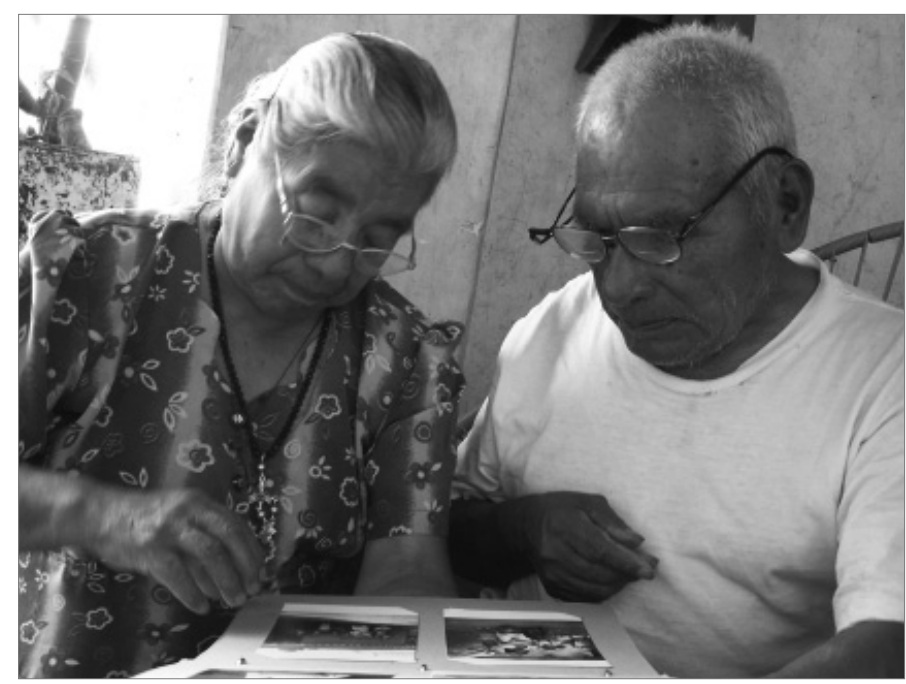

12. «Las fotografías del antropólogo». Ernenek Mejía. Yalálag, 2007.

\section{CONSIDERACIONES FINALES}

Gran parte de las imágenes de Julio de la Fuente, que se centran en mostrar los rasgos físicos y elementos de vestido, peinado, entorno, etc., sin retoques o adornos de los yalaltecas, funcionaban como una herramienta para la realización de su trabajo etnográfico y a través de su papel documental se presentaban como un instrumento que testificaba la existencia de los sujetos de conocimiento, transformándolos en objetos de estudio.

Como objetos de estudios los indígenas eran observados desde sus características culturales hasta raciales, catalogados a partir de los signos visuales de diferenciación. El antropólogo Johanes Fabian, citado en la investigación de Deborah Dorotinsky (2003), nombra «visualismo» a la práctica que suponía que poder visualizar a una sociedad y representarla gráficamente, era lo mismo que comprenderla. De esta forma, la representación de la diferencia cultural a través de las imágenes tenía como principal objetivo la auto-explicación. Los registros fotográficos de Julio de la Fuente se presentan como este intento de catalogación de la diferencia cultural, en un intento por comprenderla.

La base de la comprensión del carácter indígena era la definición de los rasgos específicos de este grupo, uno de ellos visualmente apreciado era la vestimenta, que marcaba claramente su diferenciación con los mestizos. En la obra de De la Fuente el vestido y los accesorios ganan este carácter definitorio. A partir de su estudio sobre el cambio cultural, caracterizado por la búsqueda de «elementos que asemejan y diferencian a los grupos de nuestra población [...]» (9), este autor relaciona las prendas con el apego a los modos considerados como conservadores o con el «acatrinamiento». 
Los elementos de la vestimenta indígena son vistos como señales de la preservación de las costumbres tradicionales. La búsqueda por esa caracterización lleva a De la Fuente a sacar decenas de fotografías que tipifican tanto lo tradicional como lo moderno. El cambio se percibe a través de las fotografías familiares en las cuales el autor ubica los personajes cambiantes, principalmente a los niños que, a diferencia de sus papás, ya no utilizan los trajes tradicionales, presentándose por ello como agentes del cambio cultural. Se marca a partir de la vestimenta y de los atuendos la cercanía o lejanía de los individuos a la urbanidad, y a través de ello las posibilidades o no del cambio cultural.

Las fotografías de Julio de la Fuente cumplen, entonces, la función de trascender las transformaciones y la desaparición y muerte de una cultura. Barthes en su estudio denominado La cámara lúcida (1997), sostiene que la fotografía es una afirmación de la muerte, en el sentido de que sobre el papel preparado se plasma un «doble» de la realidad, como la evidencia misma del esto-ha-sido, de la muerte. La imagen, entonces, surge como garantía de eternidad, ya que representa el doble de su referente y por ello una manera de trascender su desaparición. Así, las fotografías de De la Fuente surgen como un «monumento recordatorio» (Dorotinsky, 2003) frente a la inminente transformación del indio. Y como tal, sus imágenes guardan los recuerdos del cambio mismo, de las transformaciones que algún día desaparecerían con el indio.

El estudio de la recepción de las fotografías de Julio de la Fuente me abrió diversos caminos de análisis y conocimiento tanto de su obra como de la realidad yalalteca pasada y contemporánea. La posibilidad de haber conocido la comunidad en donde De la Fuente tomó gran parte de sus fotografías durante sus investigaciones en la Sierra Norte, me permitió observar sus fotografías de manera particular. A partir del trabajo de campo puede identificar las imágenes que faltaron en su estudio, su relación con los yalaltecas y algunas particularidades de su percepción de la comunidad. Además, a partir del testimonio de algunos yalaltecas, saber cómo lo conocieron, cómo el autor se comportaba en la comunidad y qué aprendió a hablar del zapoteco.

Desde la recepción y el álbum de fotografías que llevaba pude acercarme a la realidad de las personas de esta comunidad desde su pasado, sus historias y a partir de ellas conocer la percepción que los diferentes grupos que componen esta comunidad tienen del presente, aspecto que aún no ha sido explorado por la antropología visual.

Los usos originales de la fotografía de Julio de la Fuente, tomadas para ilustrar su trabajo antropológico y documentar el cambio cultural, fueron desde la mirada yalalteca suplantados por el uso de la fotografía como memoria social. A partir de la realidad zapoteca contemporánea las imágenes se transformaron en un baúl de recuerdos que abrieron puertas a la comprensión del cambio cultural visto desde la mirada local, posibilitando con ello comprender, desde su propia perspectiva, cómo los cambios impuestos desde las políticas indigenistas han integrado a estas comunidades a la sociedad nacional.

Se percibe entonces, que aunque los usos originales de sus fotografías son suplantados, su función de «monumento recordatorio» se refuerza frente a los cambios culturales que ha sufrido la comunidad. No sólo como recuerdos de un pasado reciente, a través de los cuales los habitantes de Yalálag percibieron los elementos de las imágenes más que su composición visual. Sin embargo es también como parte de una ideología que define y defiende determinados marcadores culturales encontrados en las imágenes que la mujer 
yalalteca retratada en contrapicado ganó poder, belleza y dignidad por ser indígena. Fue así que el «monumento recordatorio" ganó importancia, valor y el contrapicado le dio a la mujer yalalteca la dignidad que para los habitantes de este pueblo encarna su pasado.

\section{REFERENCIAS}

Aquino, Alejandra. (2002). Acción colectiva, autonomía y conflicto: la reinvención de la identidad entre los zapotecas de la Sierra Juárez. Tesis presentada para la obtención del grado de maestra en Sociología Política. México: Instituto de Investigaciones Dr. José María Luis Mora.

Barthes, Roland. (1997). La cámara lúcida. Nota sobre la fotografía. Barcelona: Paidós.

De la Fuente, Julio. (1949). Yalálag. Una villa zapoteca serrana. México: Museo Nacional de Antropología, INAH, Secretaría de Educación Pública.

Dorotinsky, Deborah. (2003). La vida en un archivo. "México Indígena» y la fotografía etnográfica de los años cuarenta en México. Tesis para la obtención del grado de doctora en Historia del Arte. México: Facultad de Filosofía y Letras, Universidad Nacional Autónoma de México.

Petroni, Mariana C. A. (2008a). La representación del indio en la obra de Julio de la Fuente. Un estudio sobre la antropología y la fotografía mexicana. Tesis presentada para la obtención del grado de maestra en antropología social. México, Centro de Estudios e Investigaciones Superiores en Antropología Social.

- (2008b). La representación del indio en las fotografías del antropólogo e indigenista Julio de la Fuente. Cultura y Representaciones sociales, revista electrónica de ciencias sociales 5 (pp. 156-176). México, año 3, septiembre.

Redfield, Robert. (1973). Tepoztlan a Mexican village: a study of a folklife. Chicago: The University of Chicago Press.

Rodríguez Gutiérrez, Marisol. (1995). «Testimonio y poder de la imagen» en Aguirre Baztán. Etnografía, Metodología cualitativa en la investigación cultural (pp. 237247). México: Alfaomega.

Sontag, Susan. (2006). Sobre la fotografía. México: Alfaguara.

Recepción: agosto de 2009 Aceptación: septiembre de 2009 